Kong. Res. J. 2(2) : 11-12, 2015

Kongunadu Arts and Science College, Coimbatore.

ISSN 2349-2694

\title{
CHARACTERIZATION OF LANTHANUM ALUMINATE NANOPARTICLES PREPARED BY SOL-GEL ROUTE
}

\author{
Gayathri, S. and B. Chandar Shekar* \\ Department of Physics, PG Research Nanotechnology Lab, Kongunadu Arts and Science Colloge, Coimbatore, \\ Tamilnadu, India. \\ *E.mail: chandar.bellan@gmail.com
}

\begin{abstract}
Lanthanum aluminate was synthesised by simple sol-gel route to get a homogenously mixed powder. Hexahydrated Lanthanum Nitrate and Aluminium Nitrate were used as precursors, heat treated to obtain a fine grained powder of Lanthanum Aluminate. The powder was calcined at $800^{\circ} \mathrm{C}$ to get fine Lanthanum Aluminate powder and then characterised by XRD, SEM and EDAS to obtain the structure, morphology and composition. The XRD revealed the formation of a crystalline phase of lanthanum aluminate with a rhombohedral structure. The SEM revealed the agglomeration of lanthanum aluminate nanoparticles and energy dispersive spectrum indicated the existence of $\mathrm{O}, \mathrm{Si}$ and $\mathrm{Al}$ in the sample. The observed results indicated the feasibility of utilizing Lanthanum aluminate nanoparticles to prepare thin film using evaporation technique which could find application as dielectric in thin film transistors.
\end{abstract}

Keywords: Lanthanum aluminate nanoparticles, sol-gel route, SEM.

\section{INTRODUCTION}

The preparation of new materials possessing desired property continuous to be a challenge nowadays. Lanthanum aluminate is one of the important materials which has received much attentation due its dielectric properties. Lanthanum aluminate can be used as resonators in microwave filter application due to its microwave dielectric property (Reaney and Iddle, 2006) and has potential applications in the areas of high frequency capacitors, magneto hydrodynamic generators, substrate for super conducting, ferro electric thin films, gas sensors, catalyst for oxidative coupling, hydrogenolysis of hydrocarbons and colossal magneto resistance (Berkstresser et al., 1993 and Sung, 1991). Normally lanthanum aluminate nanoparticles is synthesised by solid state reaction method in the temperature range of $1500-1700{ }^{\circ} \mathrm{C}$ (Kilner et al., 1978; Nguyen, 2000). In the present study an attempt has been made to prepare lanthanum aluminate at lower temperature $\left(800^{\circ} \mathrm{C}\right)$ by using a simple sol-gel method.

\section{EXPERIMENTAL}

The starting materials used were lanthanum nitrate and aluminium nitrate. Stoichiometric amounts of aluminium nitrate and lanthanum nitrate were allowed to dissolve in distilled water by gradually heating it up to $110{ }^{\circ} \mathrm{C}$, until a clear solution is obtained. This solution was quenched at room temperature to avoid phase separation. The resulting solid mass was broken into lumps and dehydrated for $24 \mathrm{~h}$ at a temperature of $80^{\circ} \mathrm{C}$ and was decomposed at a temperature of $400{ }^{\circ} \mathrm{C}$. The powder was well grinded and calcined at $800^{\circ} \mathrm{C}$.

\subsection{Characterisation of nanoparticles}

The crystallinity and crystal structure of the nanoparticles were analysed by using X Ray Diffraction. The morphology, composition and structure of the nanoparticles were examined by Scanning Electron Microscopy (SEM), and Energydispersive X-ray spectroscopy (EDS).

\section{RESULTS AND DISCUSSION}

Fig. 1 shows the XRD pattern of lanthanum aluminate nanoparticles calcined in air at $800^{\circ} \mathrm{C}$. The particles are crystalline in nature. The observed intense peaks at $2 \theta=23,33,41,48,54,59,70,75,80$, 84 and 89 are in accordance with the JCPDS card No 82-0478. These peaks correspond to reflection from rhombohedral lanthanum aluminate with perovskite structure. The particle size of the lanthanum aluminate was calculated by using Scherer formula $\mathrm{t}=0.9 \lambda / \beta \cos \theta$

where $t$ is average particle size, $\lambda$ is the wavelength of $\mathrm{Cu}-\mathrm{K} \alpha$ radiation, $\beta$ is the full width at half maximum of the diffraction peak and $\theta$ is the Bragg diffraction angle. The crystallite size of 
lanthanum aluminate calcined at $800^{\circ} \mathrm{C}$ was found to be $22 \mathrm{~nm}$.

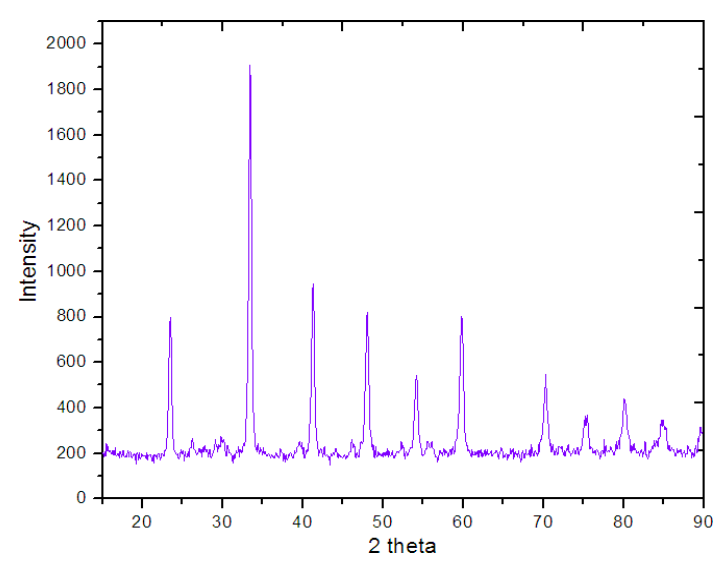

Fig. 1. XRD pattern of lanthanum aluminate nanoparticles

The morphology of the sample is observed with the help of scanning electron microscope (SEM). SEM images of lanthanum aluminate nanoparticles with different magnifications are shown in Fig. 2. Surface morphology of the as prepared lanthanum aluminate showed agglomeration of cubic like particles. The distribution of the crystallite sizes is not homogenous. It also indicates the highly crystalline nature of the synthesized particles. The characteristic peaks observed in the EDS spectrum indicated the presence of $\mathrm{La}, \mathrm{Al}$ and $\mathrm{O}$ atoms (Fig. 3).

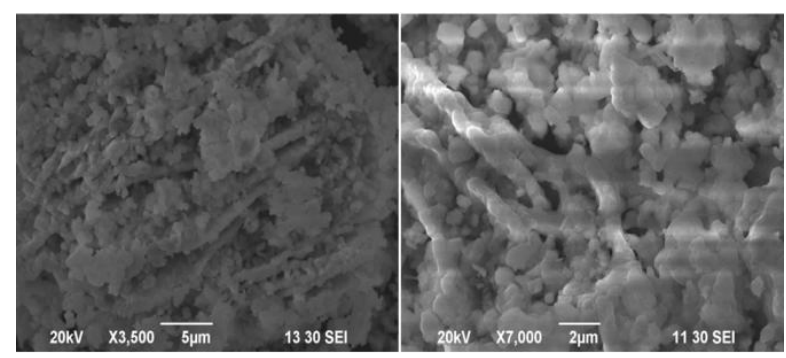

Fig. 2. SEM Images of lanthanum aluminate particles

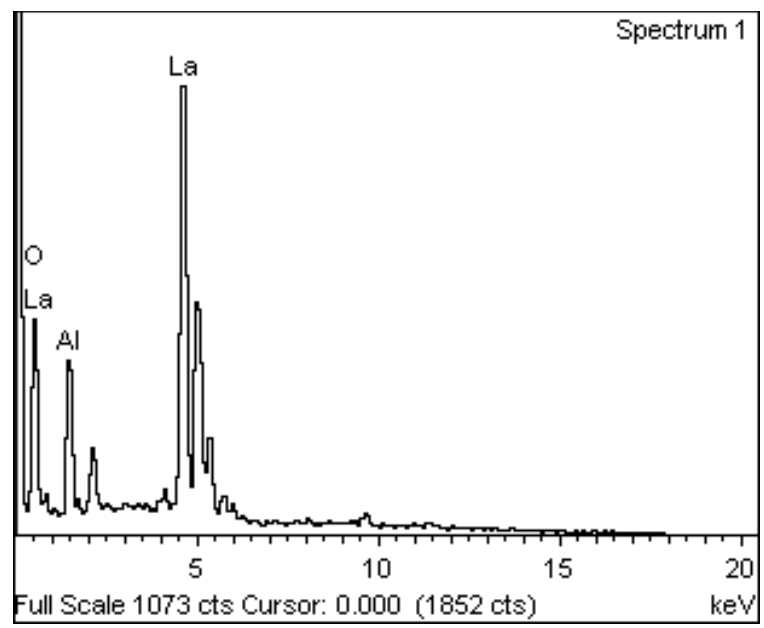

Fig. 3. EDS of lanthanum aluminate particles

\section{CONCLUSION}

Lanthanum aluminate nanoparticles were prepared by simple sol-gel method at lower temperature. The XRD pattern of lanthanum aluminate nanoparticles calcined at $800^{\circ} \mathrm{C}$ showed crystalline nature. The SEM image of lanthanum aluminate nanoparticles showed agglomeration of cubic like particles. The peaks observed in the EDS spectrum of lanthanum aluminate nanoparticles indicated the presence of $\mathrm{La}, \mathrm{Al}$ and $\mathrm{O}$ atoms.

\section{REFERENCES}

Berkstresser, G.W., Valentino, A.J. and C.D. Brandle, (1993). J. Cryst. Growth. 128: 684.

Kilner, J.A., P. Barrow, R.J. Brook and M.J. Norgett, (1978). J. Powder Sour. 3: 67.

Nguyen, T.L., M. Dokiya, S.R. Wang, H. Tagawa and T. Hashimoto, (2000). Solid State Ionics 130: 229.

Reaney, I.M. and D. Middle, (2006). J. Am. Ceram. Soc. 89: 2063.

Sung, G.Y., K.Y. Kang, and S.C. Park, (1991). J. Am. Ceram. Soc. 74: 437. 